\title{
Corrosion Resistance of Friction Stir Welded AI-Cu-Li Alloy AA2099-T8
}

\author{
Yan-Long Ma ${ }^{1,2} \cdot$ Hui-Bin $\mathrm{Xu}^{1,2} \cdot$ Zhao-Yuan Liang $^{1} \cdot$ Lei Liu $^{1}$ \\ Received: 21 March 2019 / Revised: 5 May 2019 / Published online: 10 October 2019 \\ (c) The Chinese Society for Metals (CSM) and Springer-Verlag GmbH Germany, part of Springer Nature 2019
}

\begin{abstract}
In order to study the effect of friction stir welding (FSW) on corrosion resistance of Al-Cu-Li alloy AA2099-T8, the microstructure and microhardness of FSW joints were characterized, and then, the corrosion behavior of the FSW joints was investigated by the immersion and potentiodynamic polarization tests in a $3.5 \% \mathrm{NaCl}$ solution at room temperature. It is indicated that the alloy was softened by FSW, with the lowest hardness appearing at the boundary between the nugget zone and the thermo-mechanically affected zone. When exposed to the $\mathrm{NaCl}$ solution, the FSW joint was characterized by shallow pits and was free of severe localized corrosion, probably due to dissolution of $T_{1}\left(\mathrm{~A}_{2} \mathrm{CuLi}\right)$ phase in the FSW joint. It is suggested that further work should be carried out to evaluate the galvanic coupling effect between the FSW joint and the base metal, as well as the stress corrosion cracking resistance of the FSW joint.
\end{abstract}

Keywords Frictions stir welding $(\mathrm{FSW}) \cdot \mathrm{Al}-\mathrm{Cu}-\mathrm{Li}$ alloy $\cdot$ AA2099 $\cdot$ Localized corrosion

\section{Introduction}

Aluminum-lithium (Al-Li) alloys have been increasingly used in aircraft structures due to a combination of high specific strength and modulus, low rate of fatigue crack propagation [1-3] and relatively low cost compared with carbon fiber reinforced polymer composites [4]. With the application of Al-Li alloys in aerospace industry, the weldability of these alloys becomes an importance concern. Fusion welding of $\mathrm{Al}-\mathrm{Li}$ alloys often causes hot cracks and voids in the welded joint; arc welding, laser welding and electron beam welding are not suitable for the welding of Al-Li alloys due to their strong softening effect on the welded joint [5]. Friction stir welding (FSW), invented by The Welding Institute (TWI) in 1991, is one of the most widely used welding techniques for aluminum alloys [6]. FSW is promising for joining $\mathrm{Al}-\mathrm{Li}$ alloys because FSW takes place below the melting

Available online at http://link.springer.com/journal/40195

Yan-Long Ma

myl@ cqut.edu.cn

1 College of Materials Science and Engineering, Chongqing University of Technology, Chongqing 400054, China

2 Chongqing Municipal Engineering Research Center of Institutions of Higher Education for Special Welding Materials and Technology, Chongqing University of Technology, Chongqing 400054, China point of the base metal, and therefore, the volatilization loss of lithium can be avoided [7-9].

The microstructural evolution in FSW is different from that in fusion welding process due to the combination of plastic deformation and thermal cycle of FSW. It is now generally known that four different regions exist in the welded joint, i.e., base metal (BM), heat-affected zone (HAZ), thermo-mechanically affected zone (TMAZ) and nugget zone (NZ). Previous work on FSW of conventional aluminum alloys such as AA2024 [10, 11] and AA7075 [12] suggests that the welds are generally more susceptible to pitting corrosion, exfoliation corrosion, intergranular corrosion and stress corrosion cracking. It is now generally accepted that corrosion of friction stir welded aerospace aluminum alloys is one of the major concerns for the application of FSW on aircraft [12].

Due to the high electrochemical activity of lithium and lithium-containing alloy phases, the corrosion behavior of Al-Li alloys has attracted extensive attention. Proton et al. [13] studied the influence of artificial aging on the corrosion behavior of $2050 \mathrm{Al}-\mathrm{Li}$ alloy, relating the corrosion behavior of the alloy to the distribution of $T_{1}$ precipitates. Guérin et al. [14] studied the corrosion behavior of 2050 $\mathrm{Al}-\mathrm{Li}$ alloy in a $\mathrm{NaCl}$ solution, considering not only the structure of the precipitates but also the nature of interfaces and the grain characteristics. Zhang et al. [15, 16] studied the influence of grain structure on the corrosion behavior of 
2A97-T3 Al-Cu-Li alloy, finding that grain-stored energy played a more decisive role in corrosion propagation compared to $T_{1}$ phase precipitate.

In addition, a few researchers also investigated the corrosion behavior of friction stir welded $\mathrm{Al}-\mathrm{Li}$ alloys. Proton et al. [17] found that the NZ of the 2050-T3 Al-Li alloy FSW joint was the most susceptible region to localized corrosion. Zhang et al. [18], however, found that the TMAZ was more susceptible to localized corrosion than other zones.

AA2099, a typical third-generation $\mathrm{Al}-\mathrm{Cu}-\mathrm{Li}$ alloy, designated in 2003, has been used on Airbus 380 (AA2099T8E67 extrusions and AA2099-T8E77 plates) [3]. Previous work suggests that AA2099 alloy suffers from localized corrosion associated with $\mathrm{Al}-\mathrm{Fe}-\mathrm{Mn}-\mathrm{Cu}-(\mathrm{Li})$ constituent particles $[19,20]$ and heterogeneously distributed $T_{1}\left(\mathrm{~A}_{2} \mathrm{CuLi}\right)$ precipitates [21, 22]. Recently, Chen et al. [8] have investigated the microstructure of FSW $2099 \mathrm{Al}-\mathrm{Cu}-\mathrm{Li}$ alloy, revealing significant difference between the characteristic zones of the welded joint. Specifically, a "W"-shaped microhardness profile was revealed across the welded joint, with a minimum microhardness at the boundary between the TMAZ and NZ; the precipitates in the BM including $T_{1}, \theta^{\prime}$ $\left(\mathrm{Al}_{2} \mathrm{Cu}\right)$ and $\delta^{\prime}\left(\mathrm{Al}_{3} \mathrm{Li}\right)$ were transformed into fine $\delta^{\prime}$ in the NZ, TMAZ and HAZ. However, to date, the effect of FSW on the corrosion resistance of AA2099 alloy has not been reported. Thus, the corrosion resistance of FSW AA2099-T8 alloy in a $3.5 \% \mathrm{NaCl}$ solution was investigated in this work.

\section{Experimental}

AA2099-T8 alloy plates of $3 \mathrm{~mm}$ thickness (cut from an extruded profile) were used, with the chemical composition of the alloy given in Table 1. FSW was performed on a revamped vertical milling machine. The stir tool was made of H13 steel with a shoulder diameter of $15 \mathrm{~mm}$, a pin diameter of $5 \mathrm{~mm}$ and pin length of $2.7 \mathrm{~mm}$. The pin has a cylinder shape with a screw thread. A constant rotation speed of $1100 \mathrm{rpm}$ and a travel speed of $44 \mathrm{~mm} / \mathrm{min}$ were employed to obtain reasonably good welding quality.

Before the corrosion tests, the specimens were ground sequentially with 400-, 600-, 800-, 1200- and 2500-grit silicon carbide papers and then polished using $1-\mu \mathrm{m}$ diamond paste. Then, the specimens were masked with lacquer, allowing only the area of interest being exposed to the electrolyte. The immersion test was performed in a $3.5 \% \mathrm{NaCl}$ solution at room temperature $\left(\sim 25^{\circ} \mathrm{C}\right)$, with the open circuit potential (OCP) being recorded. The purpose of the immersion test is to introduce localized corrosion in different regions of the joint. Both the surface and cross section of the joint were tested. The corrosion morphology of different regions of the joint was mainly observed from the cross section because the characteristic zones were more readily identified from the cross section and the variation in microstructure/corrosion resistance through the thickness of the welded joint can be examined conveniently.

Potentiodynamic polarization test was performed on the top surface of the base metal and the NZ in a $3.5 \mathrm{wt} \% \mathrm{NaCl}$ solution, with the specimen, a saturated calomel electrode (SCE) and a platinum plate as working electrode, reference electrode and auxiliary electrode, respectively. The specimen surface was sealed with epoxy resin to leave an area of $1 \mathrm{~cm}^{2}$ to the electrolyte. The polarization was started from -100 to $500 \mathrm{mV}$ with respect to the OCP at a scanning rate of $0.5 \mathrm{mV} / \mathrm{s}$. Before polarization, the specimen was immersed in the solution for $30 \mathrm{~min}$ to reach a relatively stable OCP. The surfaces of the TMAZs and HAZs are relatively small, and the related boundaries (TMAZ/NZ, TMAZ/HAZ and HAZ/BM) could not be accurately defined by the methods employed in the present work. Therefore, the electrochemical properties of the TMAZs and HAZs were not included in this work.

The microstructural analysis of the FSW joint before and after the corrosion tests was performed on an optical microscope (Leica DMI5000M) and a scanning electron microscope (Zeiss Sigma HD) equipped with energy-dispersive spectroscopy (EDS) facilities. Keller's reagent ( $2 \mathrm{~mL}$ hydrofluoric acid, $3 \mathrm{~mL}$ hydrochloric acid, $5 \mathrm{~mL}$ nitric acid and $100 \mathrm{~mL}$ distilled water) was used to etch the specimens. After etching in the Keller's reagent, the specimen surface was gently wiped using a $30 \mathrm{vol} \% \mathrm{HNO}_{3}$ solution to remove the corrosion products. Microhardness test was conducted on the cross-sectional plane, along the middle line of the plate, in the horizontal direction, using an HVS-1000 Vickers indenter, with an applied load of $100 \mathrm{~g}$ for $15 \mathrm{~s}$.

\section{Results}

Figure 1 shows optical micrograph of the cross section of the FSW joint at low magnification, revealing the BM, HAZ, TMAZ and NZ, as labeled. No evident voids or cracks were observed on the selected section. At increased magnification, it was found that the optical microstructure of the HAZ (Fig. 2a) was similar to that of the BM, which was characterized by fine and elongated grains along the
Table 1 Chemical composition of AA2099-T8 alloy (wt\%)

\begin{tabular}{lllllllllll}
\hline Elements & $\mathrm{Cu}$ & $\mathrm{Li}$ & $\mathrm{Zn}$ & $\mathrm{Mg}$ & $\mathrm{Mn}$ & $\mathrm{Fe}$ & $\mathrm{Ti}$ & $\mathrm{Si}$ & $\mathrm{Zr}$ & $\mathrm{Al}$ \\
\hline Content & 2.70 & 1.69 & 0.65 & 0.27 & 0.315 & 0.065 & 0.025 & 0.035 & 0.08 & Balance \\
\hline
\end{tabular}




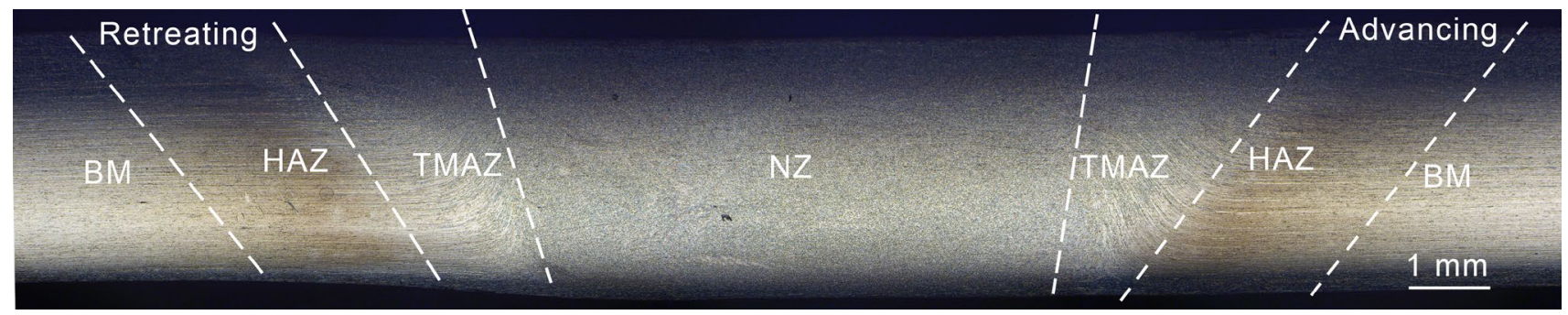

Fig. 1 Optical micrograph of the cross section of the friction stir welded AA2099-T8 aluminum alloy at low magnification. The boundaries between each of the regions are schematically indicated by the dashed lines
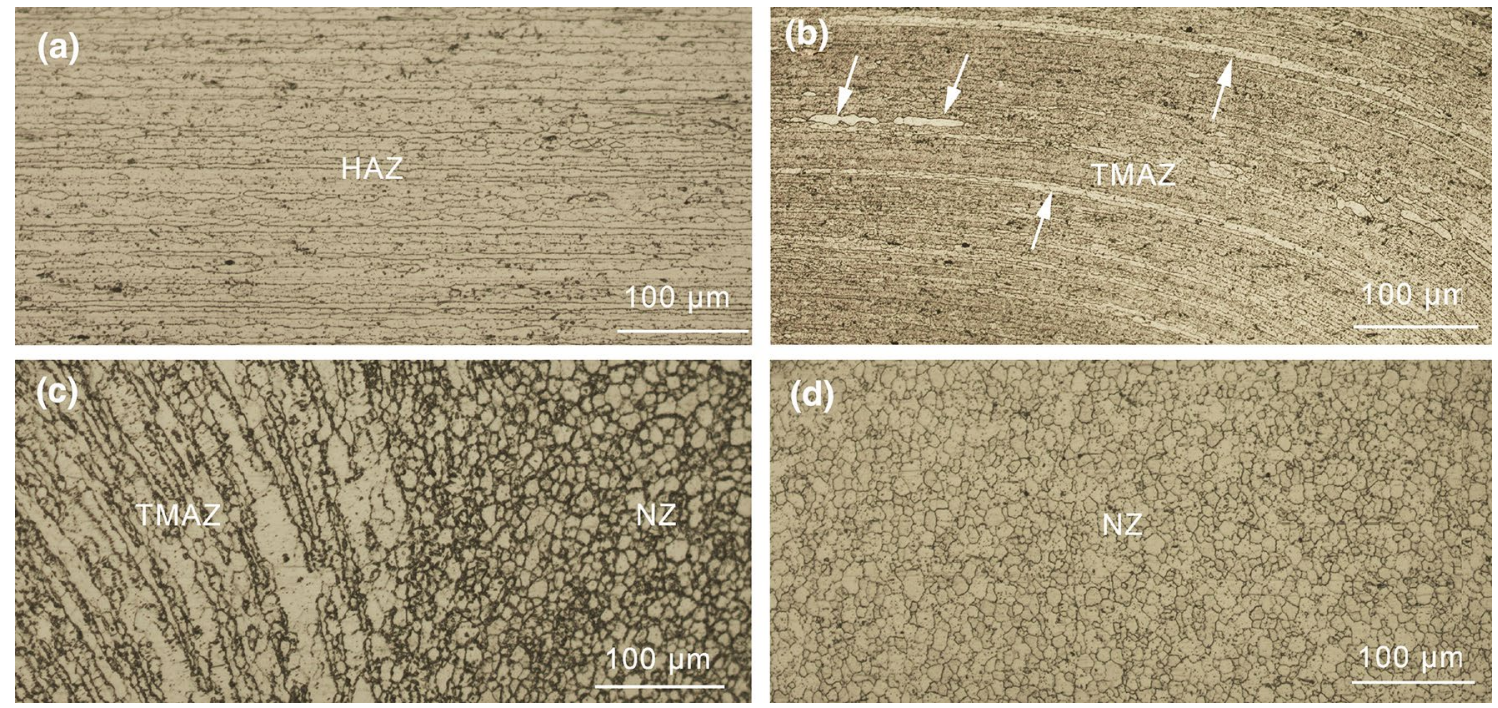

Fig. 2 Optical micrographs of the cross section of the friction stir welded AA2099-T8 aluminum alloy at increased magnification (retreating side): a HAZ; b TMAZ; c TMAZ/NZ; d NZ

extrusion direction. Flow of material along the rotation direction as a consequence of plastic deformation was evident in the TMAZ (Fig. 2b). Besides, grains started to coarsen (indicated by the arrows in Fig. 2b) in this region due to the heat effect generated by severe plastic deformation. When approaching the NZ, deformed and coarsened grains mixed with recrystallized grains (Fig. 2c). Fine and fully recrystallized grains were generated in the NZ, which was subjected to the most severe plastic deformation (Fig. 2d).

A "W"-shaped microhardness profile was revealed across the cross section of the FSW joint (Fig. 3). The microhardness distribution was related to the degree of recrystallization, the size of the grains and the type/distribution of strengthening precipitates, in different regions of the FSW joint. According to the microstructural characterization of FSW AA2099-T8 Al-Li alloy [8], the main precipitates in the BM included $T_{1}, \theta^{\prime}$ and $\delta^{\prime}$, which gave the highest microhardness of the BM; the main precipitates in the NZ, TMAZ and HAZ were fine $\delta^{\prime}$ phase and the volume fraction of $\delta^{\prime}$

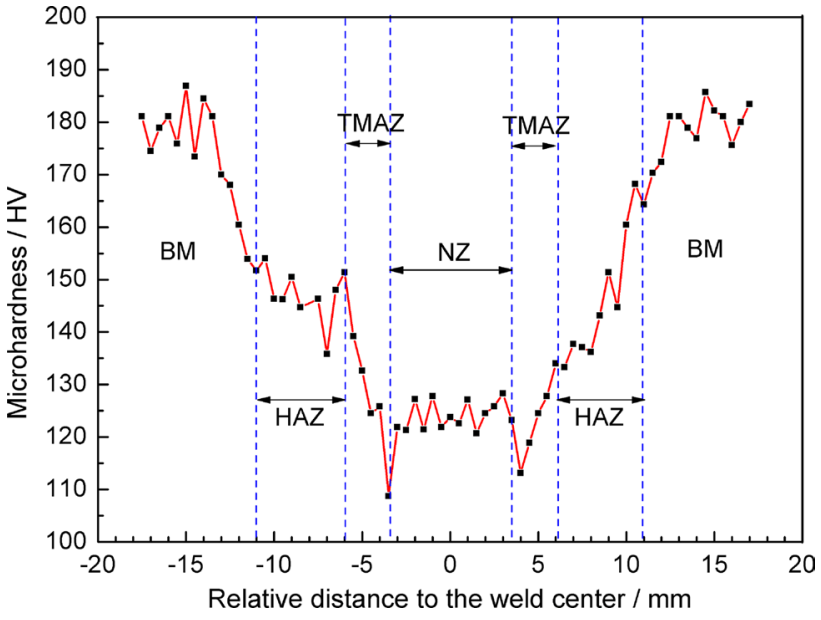

Fig. 3 Microhardness of the welded joint measured from the half thickness of the plate 
phase in these regions was comparable, suggesting that other factor(s) influenced the microhardness distribution.

According to Fig. 2d, full recrystallization occurred in the NZ, leading to the formation of strain-free, equi-axed, recrystallized grains and therefore reduced microhardness. Since little recrystallization occurred in the HAZ and TMAZ (Fig. 2a, b), the strain hardening effect during the extrusion process and the subsequent $\mathrm{T} 8$ treatment remained to a certain degree. Therefore, the microhardness of the HAZ and TMAZ was lower than that of the BM but higher than that of the NZ. In the boundary regions between the TMAZ and NZ (Fig. 2c), however, the grains were significantly coarsened, probably due to abnormal growth of recrystallized grains, resulting in the lowest microhardness. Consequently, the minimum microhardness appeared at the boundary between TMAZ and NZ; the NZ had the second lowest microhardness; the TMAZ had the third lowest microhardness; the microhardness of the HAZ was higher than that of the TMAZ but lower than that of the BM.

The cross section of the FSW joint was exposed to a 3.5\% $\mathrm{NaCl}$ solution for $5 \mathrm{~h}$ to introduce localized corrosion, and the surface morphology of the specimen was visually monitored every $15 \mathrm{~min}$. Fine gas bubbles started to appear in the $\mathrm{BM}$ after about $30 \mathrm{~min}$ of immersion while there were no evident features in the FSW joint during this period. As reported previously, such gas bubbles correspond to continuous localized corrosion in AA2099-T8 alloy [20]. This suggests that there was continuous localized corrosion in the $\mathrm{BM}$, but there was no such localized corrosion in the FSW joint after immersion for $30 \mathrm{~min}$.

With further immersion up to $150 \mathrm{~min}$, there was no evident change in the surface appearance, except that the number of the gas bubbles significantly decreased. This is because some of the continuous localized corrosion stopped or slowed down after prolonged immersion, probably due to limited access of corrosive electrolyte to the bottom of the corrosion pits. Thereafter, the specimen surface became dark, with the BM being darker than the FSW joint. As suggested latter, the change of the specimen surface appearance is associated with the initiation of localized corrosion at the sites of intermetallic particles (IMPs) and building up of corrosion products. Therefore, the relatively darker surface appearance in the BM suggests severer localized corrosion in the BM.

Figure 4 shows optical micrographs of the cross section of the FSW joint of AA2099-T8 aluminum alloy after immersion in the $3.5 \% \mathrm{NaCl}$ solution for $5 \mathrm{~h}$. Fine dark spots were revealed on the exposed surface, with the population density of the dark spots increasing in order from the NZ to the TMAZ and the HAZ. The population density of the dark spots in the BM was slightly higher than that in the NZ but slightly lower than that in the TMAZ and HAZ. In addition, dark line features were occasionally revealed in the BM (Fig. 4d) and such features were not revealed in the FSW joint.

Figure 5a, b shows SEM micrographs of typical regions containing dark spots and dark line features, respectively. It is evident that the dark spots observed on the specimen surface corresponded to metastable pits, which were caused either by anodic dissolution of IMPs or by dissolution of the alloy matrix adjacent to IMPs (Fig. 5a). Severe corrosion attack in elongated grains was revealed in the region containing dark line features (Fig. 5b), suggesting continuous localized corrosion. The behavior and mechanism of the continuous localized corrosion were reported previously [20-22].

The immersion test suggests that the FSW joint in general and the NZ in particular show higher resistance to pitting corrosion than the BM. In order to validate the improved corrosion resistance of the NZ, a defined area of $1 \mathrm{~cm}^{2}$, on the top surface of the FSW joint, in the center of the NZ, was exposed to the $3.5 \% \mathrm{NaCl}$ solution for $5 \mathrm{~h}$, with the OCP being recorded during the immersion. For comparison, the same immersion test was carried out on the BM. It was found that the stabilized OCP of the NZ was $-0.68 \mathrm{~V}$ (SCE), which is about $40 \mathrm{mV}$ (SCE) more positive than that of the BM (Fig. 6).

According to previous work on the corrosion resistance of AA2099 alloy with different tempers [23], the increased OCP in the NZ was probably associated with the dissolution of $T_{1}$ precipitates. Figure 7 compares the surface morphology of the $\mathrm{NZ}$ and BM after immersion in the $3.5 \%$ solution for $5 \mathrm{~h}$. No special features were revealed in the NZ except for small pits associated with IMPs (Fig. 7a). In contrast, several continuous localized corrosion sites were revealed in the BM (Fig. 7b).

The potentiodynamic polarization curves of the NZ and $\mathrm{BM}$ are compared in Fig. 8. Compared with that of the BM, the curve of the NZ is shifted to the directions of higher potential and lower current density, suggesting decreased corrosion susceptibility. There is a passivation/transpassivation transition occurring at $\sim 100 \mathrm{mV}$ above the OCP for the BM (indicated by the arrow in Fig. 8). Such passivation/ transpassivation transition is not always reproducible and is related to the initiation and propagation of the severe localized corrosion.

The corrosion morphology of the specimens after potentiodynamic polarization is distinctly different for the $\mathrm{NZ}$ and BM (Fig. 9). The corrosion pits in the BM were deep and highly localized (Fig. 9a). As reported previously [23], such localized corrosion in the BM was associated with heterogeneous plastic deformation and consequently preferential precipitation of $T_{1}$ phase in specific grains. In contrast, the corrosion pits in the NZ were relatively shallower and more uniform (Fig. 9b). At increased magnification (Fig. 9c, d), it was found that the NZ was mainly characterized by intergranular corrosion. 

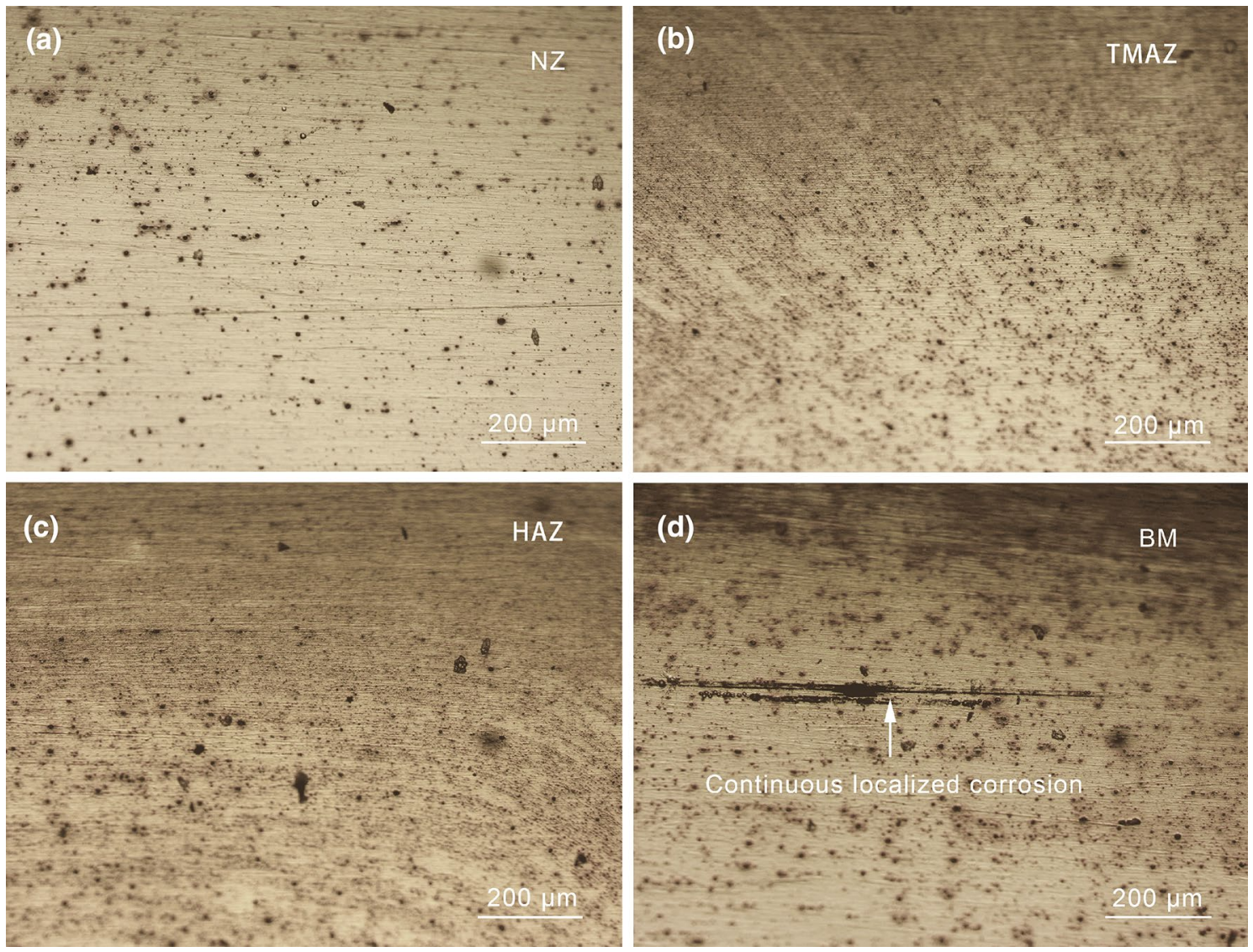

Fig. 4 Optical micrographs of the cross section of the friction stir welded AA2099-T8 aluminum alloy after immersion in $3.5 \% \mathrm{NaCl}$ solution for 5 h: a NZ; b TMAZ; c HAZ; d BM
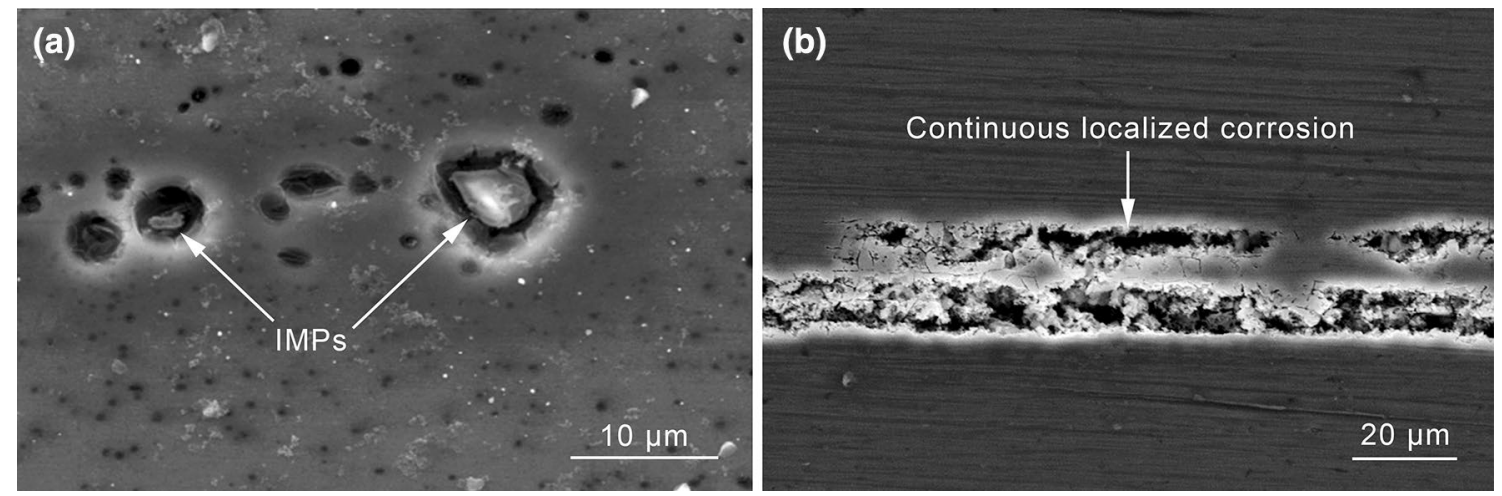

Fig. 5 Scanning electron micrographs of the cross section of the friction stir welded AA2099-T8 aluminum alloy after immersion in 3.5\% NaCl solution for $5 \mathrm{~h}$ : a typical corrosion pits associated with IMPs; $\mathbf{b}$ continuous localized corrosion observed in the base metal

\section{Discussion}

The results indicate that the FSW joint generally showed higher resistance to pitting corrosion than the BM for AA2099-T8 alloy. There are two reasons for this: Firstly, it is known that $T_{1}$ phase is very active [22] and is one of the major reasons for the initiation and propagation of localized corrosion in Al-Li alloys [13, 14, 24-27]. Therefore, the dissolution of $T_{1}$ precipitates in the FSW joint, particularly in the NZ, would improve the corrosion resistance of the alloy. Secondly, most constituent particles were 


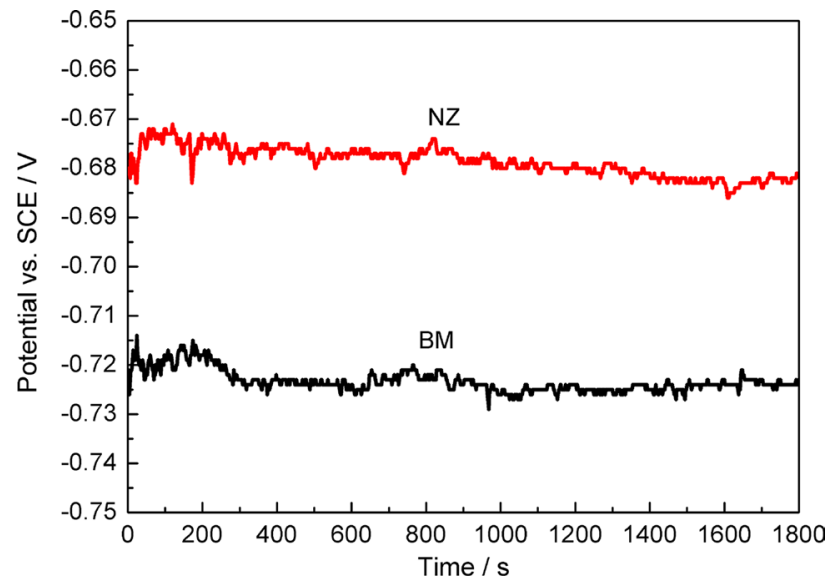

Fig. 6 Open circuit potentials of the BM and the NZ recorded during immersion in $3.5 \% \mathrm{NaCl}$ solution

refined by the severe plastic deformation and redistributed uniformly in the FSW joint, which further promoted uniform corrosion of the alloy.

The results of this work seem to contradict with the work of Proton et al. [17] on 2050-T3 FSW joint and Zhang et al. [18] on 2A97-T3 FSW joint. Proton et al. [17] found that the NZ had the highest corrosion susceptibility and was characterized by both intergranular corrosion and intragranular corrosion. Zhang et al. [18], however, found that the TMAZ edges adjacent to the HAZ were the most susceptible regions to corrosion attack and both intergranular corrosion and intragranular corrosion were observed. It is speculated that the temper of the alloy prior to FSW is mainly responsible for such difference. It is noticed that the investigations of Proton et al. and Zhang et al. were based on the alloys with T3 temper, which is associated with cold working and natural aging. However, the current study was based on T8 temper, which is associated with cold working and artificial aging.

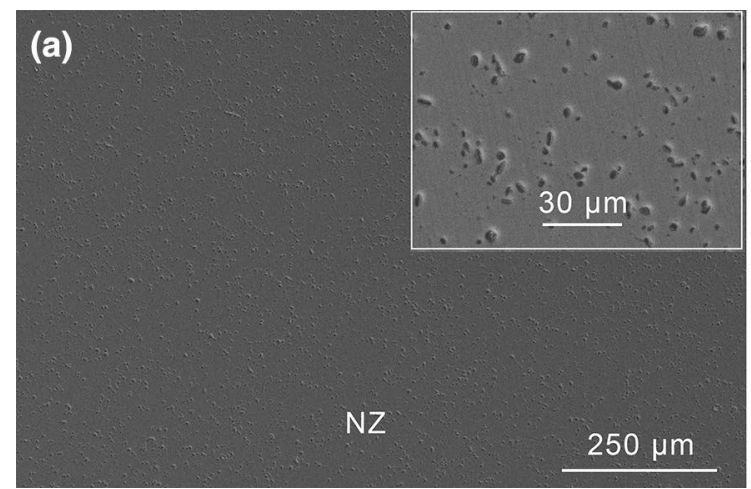

For T3-tempered alloy, the strengthening precipitates such as $T_{1}$ did not fully precipitate in the BM, while FSW promoted the precipitation and coarsening of the strengthening precipitates within the FSW joint, particularly in the TMAZ and HAZ. As a consequence, the BM was severely underaged while the other regions of the joint were nearly peak-aged or overaged. Increased volume fraction of strengthening precipitates such as $T_{1}$ resulted in increased corrosion susceptibility in the welded joint. For T8 temper, however, the situation is just reversed. As suggested in the literature [8], most of $T_{1}$ precipitates would dissolve into the alloy matrix in the HAZ, TMAZ and NZ during FSW for AA2099-T8 alloy. Consequently, the FSW joint showed better corrosion resistance than the BM.

It should be noted that although the FSW joint generally has higher resistance to pitting corrosion than the BM, it does not necessarily mean that FSW has improved the

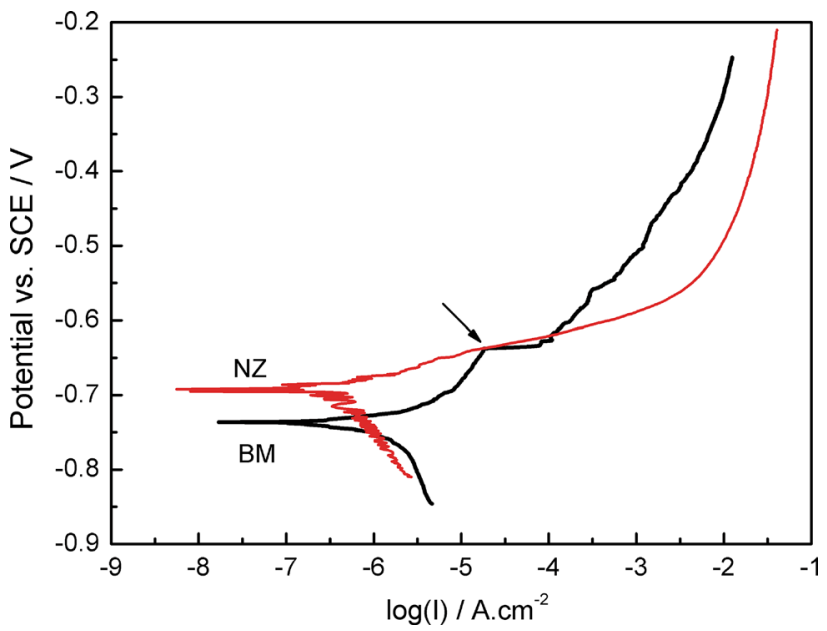

Fig. 8 Potentiodynamic polarization curves of the BM and the FSW $\mathrm{NZ}$ when potentiodynamically polarized from -100 to $500 \mathrm{mV}$ $(\mathrm{OCP})$ at a scanning rate of $0.5 \mathrm{mV} / \mathrm{s}$ in $3.5 \mathrm{wt} \% \mathrm{NaCl}$ solution

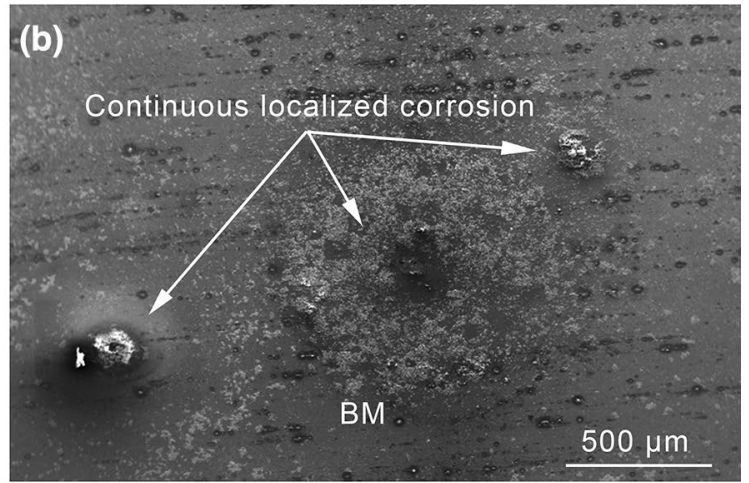

Fig. 7 Scanning electron micrographs of the top surfaces of the $\mathbf{a} \mathrm{NZ}, \mathbf{b} \mathrm{BM}$ after immersion in $3.5 \% \mathrm{NaCl}$ solution for $5 \mathrm{~h}$ 

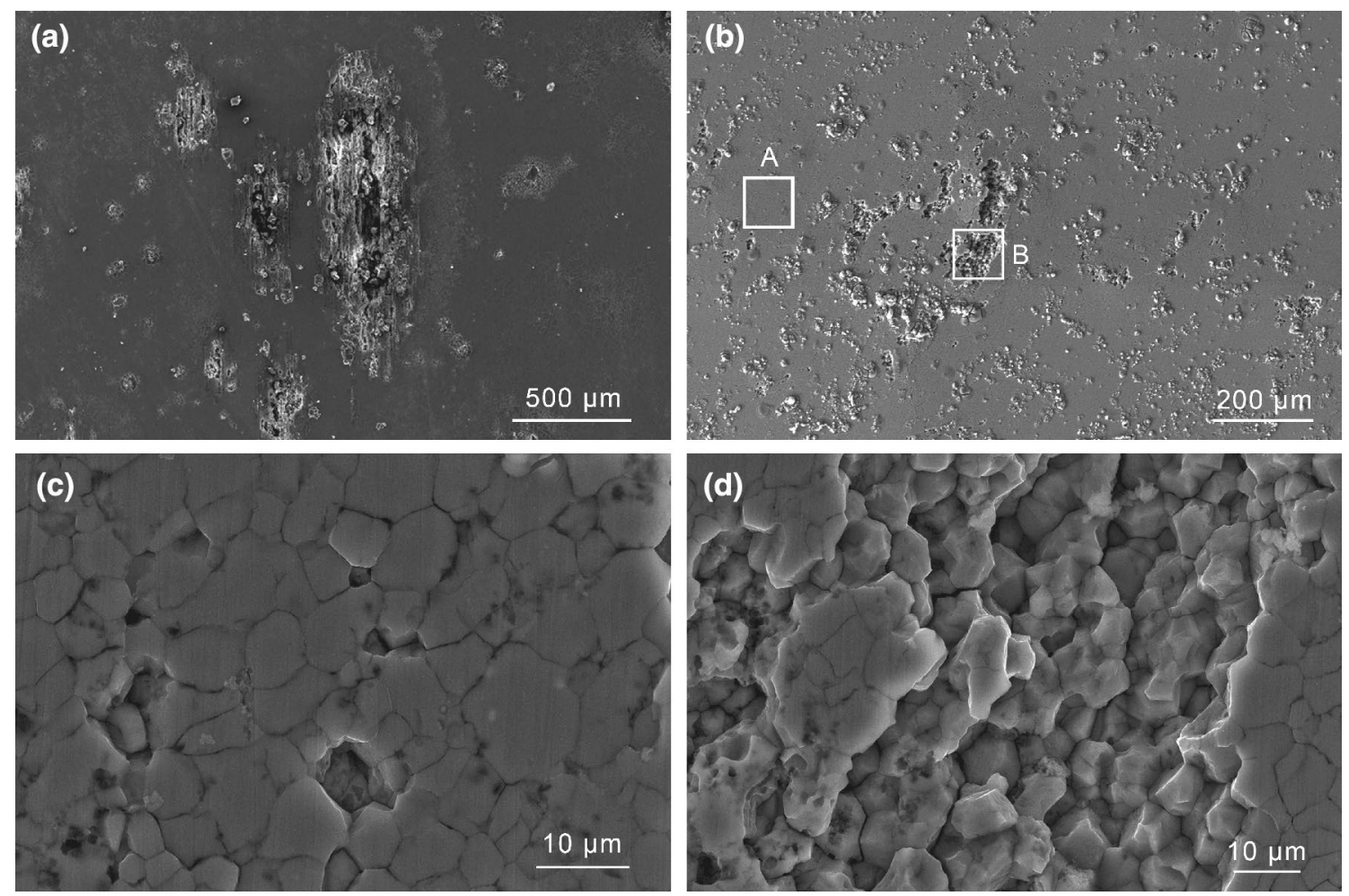

Fig. 9 Scanning electron micrographs of the top surfaces of the BM (a) and NZ (b) after polarization from - 100 to $500 \mathrm{mV}(\mathrm{OCP})$ at a scanning rate of $0.5 \mathrm{mV} / \mathrm{s}$ in $3.5 \mathrm{wt} \% \mathrm{NaCl}$ solution; $\mathbf{c}$ and $\mathbf{d}$ are the framed areas $\mathrm{A}$ and $\mathrm{B}$ at increased magnification

corrosion resistance of the welded structure. Due to the difference in the corrosion potentials between HAZ, TMAZ, $\mathrm{NZ}$ and BM, the galvanic coupling effect between each zone, and between the whole joint and the rest of the BM, may not be neglected under service conditions. Besides, stress corrosion cracking (SCC) is an important concern for the FSW joints. The impact of the changes in the microstructure, electrochemistry and residual stress in the FSW joint on the SCC of the alloy is still unknown and will be the subject of our future work.

\section{Conclusion}

AA2099-T8 alloy plates of $3 \mathrm{~mm}$ thickness were successfully welded by FSW. The microhardness of FSW joint exhibited a "W"-shaped profile, indicating the drop of mechanical properties. The minimum microhardness $(110 \mathrm{HV})$ occurred in the boundary regions between the NZ and TMAZ. When subjected to immersion in $3.5 \% \mathrm{NaCl}$ solution, the corrosion morphology of the FSW joint was characterized by fine corrosion pits associated with IMPs; continuous localized corrosion, which is typical for AA2099-T8 alloy, was not detected in the FSW joint. A distinctly different corrosion morphology was revealed after potentiodynamic polarization test in the $3.5 \% \mathrm{NaCl}$ solution, where the corrosion pits in the base metal were much deeper and more severe than the nugget zone. The nugget zone was mainly characterized by intergranular corrosion after the potentiodynamic polarization test.

Acknowledgements The authors acknowledge the Basic and Frontier Research Program of Chongqing (Grant Nos. cstc2016jcyjA0490 and cstc2017jcyjAX0285).

\section{References}

[1] E. Balducci, L. Ceschini, S. Messieri, S. Wenner, R. Holmesta, Mater. Sci. Eng. A 707, 221 (2017)

[2] Y. Deng, J. Bai, X. Wu, G. Huang, L. Cao, L. Huang, J. Alloys Compd. 723, 661 (2016)

[3] P.S. De, R.S. Mishar, J.A. Baumann, Acta Mater. 59, 5946 (2011)

[4] B.I. Rodgers, P.B. Prangnell, Acta Mater. 108, 55 (2016)

[5] O. Di, Aeronaut. Manuf. Technol. 9, 90 (2006). (in Chinese)

[6] G. Wang, Y. Zhao, Y. Hao, J. Mater. Sci. Technol. 34, 73 (2018)

[7] H. Zhang, D. Kong, X. Chen, J. Cao, Y. Zhao, J. Huang, Trans. China Weld. Inst. 33, 41 (2012). (in Chinese)

[8] X. Chen, Z. Zheng, Z. Ye, X. Kong, Rare Met. Mater. Eng. 47, $1786(2018)$

[9] J. Zhang, X.S. Feng, J.S. Gao, H. Huang, Z.Q. Ma, L.J. Guo, J. Mater. Sci. Technol. 34, 219 (2018)

[10] W. Wang, T. Li, K. Wang, J. Cai, K. Qiao, J. Mater. Eng. Perform. 25, 1820 (2016)

[11] J. Kang, R. Fu, G. Luan, C. Dong, M. He, Corros. Sci. 52, 620 (2010) 
[12] A.C. Umamaheshwer Rao, V. Vasu, M. Govindaraju, K.V. Sai Sriadh, Trans. Nonferr. Met. Soc. China 26, 1447 (2016)

[13] V. Proton, J. Alexis, E. Andrieu, J. Delfosse, A. Deschamps, F. De Geuser, M.C. Lafont, C. Blanc, Corros. Sci. 80, 494 (2014)

[14] M. Guérin, J. Alexis, E. Andrieu, L. Laffont, W. Lefebvre, G. Odemer, C. Blanc, Corros. Sci. 102, 291 (2016)

[15] X. Zhang, X. Zhou, T. Hashimoto, J. Lindsay, O. CillCa, C. Luo, Z. Sun, X. Zhang, Z. Tang, Corros. Sci. 116, 14 (2017)

[16] X. Zhang, X. Zhou, Y. Ma, G.E. Thompson, C. Luo, Z. Sun, X. Zhang, Z. Tang, Surf. Interface Anal. 48, 745 (2016)

[17] V. Proton, J. Alexis, E. Andrieu, J. Delfosse, M.C. Lafont, C. Blanc, Corros. Sci. 73, 130 (2013)

[18] X. Zhang, B. Liu, X. Zhou, J. Wang, C. Luo, Z. Sun, Z. Tang, F. $\mathrm{Lu}$, Corrosion 8, 988 (2017)

[19] Y. Ma, X. Zhou, G.E. Thompson, T. Hashimoto, P. Thomson, M. Fowles, Mater. Chem. Phys. 126, 46 (2011)
[20] Y. Ma, X. Zhou, W. Huang, G.E. Thompson, X. Zhang, C. Luo, Z. Sun, Mater. Chem. Phys. 161, 201 (2015)

[21] Y. Ma, X. Zhou, W. Huang, Y. Liao, X. Chen, X. Zhang, G.E. Thompson, Corros. Eng. Sci. Technol. 50, 420 (2015)

[22] Y. Ma, X. Zhou, Y. Liao, Y. Yi, H. Wu, Z. Wang, W. Huang, Corros. Sci. 107, 41 (2016)

[23] Y. Ma, X. Zhou, X. Meng, W. Huang, Y. Liao, X. Chen, Y. Yi, X. Zhang, G.E. Thompson, Trans. Nonferr. Met. Soc. China 26, 1472 (2016)

[24] R.G. Buchheit, J. Electrochem. Soc. 142, 3994 (1995)

[25] R.G. Buchheit, J.P. Moran, G.E. Stoner, Corrosion 46, 610 (1990)

[26] X. Zhang, X. Zhou, T. Hashimoto, B. Liu, C. Luo, Z. Sun, Z. Tang, F. Lu, Y. Ma, Corros. Sci. 132, 1 (2018)

[27] J.V. de Sousa Araujo, U. Donatus, F.M. Queiroz, M. Terada, M.X. Milagre, M.C. de Alencar, I. Costa, Corros. Sci. 133, 132 (2018) 